\title{
ЭКСПЕРИМЕНТАЛЬНОЕ ИССЛЕДОВАНИЕ НЕСТАЦИОНАРНОГО ГОРЕНИЯ ПРОПАНО-ВОЗДУШНОЙ СМЕСИ В ТРУБЕ С КОЛЬЦЕВЫМИ ПЕРЕГОРОДКАМИ
}

\author{
С. А. Лисаков, А. И. Сидоренко, Е. В. Сыпин, Ю. А. Галенко, А. Н.Павлов
}

В результате выполнения работ проведено экспериментальное исследование процесса нестационарного горения стехиометрической пропано-воздушной смеси. Разработана конструкция установки для проведения экспериментальных взрывов и предложена методика проведения исследования. Реакционный сосуд экспериментальной установки представляет собой трубу с одним открытым концом, внутренним диаметром 0,5 м и длиной 4 метра. $B$ реакционном сосуде размещались кольцевые перегородки с шагом установки $S=0.5 \mathrm{~m} \mathrm{и} \mathrm{сте-}$ пенью затенения сечения $B R=0.3$. Экспериментальное исследование выполнялось для различного числа перегородок и источников воспламенения с различной энергией. С увеличением числа перегородок максимальная скорость фронта пламени практически линейно возрастает от 35 м/с для 1 перегородки до 240 м/с для 7 перегородок. При добавлении одной дополнительной перегородки максимальная скорость фронта пламени увеличивается приблизительно на $35 \mathrm{~m} / \mathrm{c}$. В результате исследования выполнена проверка адекватности разработанной ранее компьютерной модели на полученных экспериментальных данных. Разработанная компьютерная модель является адекватной и применима для расчета параметров нестационарного горения в трубах с регулярными препятствиями. Относительная погрешность расчета скорости фрронта пламени не превышает $18 \%$.

Ключевые слова: Нестационарное горение, пропано-воздушная смесь, скорость фрронта пламени, компьютерное моделирование, труба с кольцевыми перегородками, степень затенения сечения, угольная шахта, электровоспламенитель, пиротехнический воспламенитель, реакционный сосуд.

\section{ВВЕДЕНИЕ}

В Бийском технологическом институте ведется разработка автоматической системы взрывоподавления на базе оптикоэлектронных датчиков, способной оценивать скорость фронта пламени и оперативно принимать решение по способу локализации горения до перехода его в детонацию $[1,2]$. Основной областью применения подобных систем является горнодобывающая промышленность [3].

Для угольных шахт ускорение пламени и переход пламени от десрлаграции к детонации происходит при наличии ряда фракторов, влияющих на возникновение нестационарного турбулизированного горения, в зависимости от наличия различных препятствий, геометрических параметров шахты и формы выработок, возможного воздействия потока вентиляционного воздуха $[2,4,5]$. Препятствиями в угольных шахтах являются крепь выработок и различное оборудование. Расположение крепи в выработках имеет регулярную структуру и строго регламентировано [6], что позволяет удобно исследовать ее влияние на турбулентное горение.
Коллективом авторов проведены работы по компьютерному моделированию процесса нестационарного горения метано-воздушной смеси в условиях угольной шахты [2]. Однако для подтверждения результатов моделирования требуется наличие экспериментальных данных.

Поэтому в разряд актуальных выдвигается задача экспериментального исследования нестационарного горения горючей смеси в зависимости от параметров турбулизирующих препятствий. Это позволит выполнить проверку адекватности разработанной модели; кроме того, полученные данные дополнят уже известные сведения о характере ускорения пламени в трубах с кольцевыми перегородками.

Целью данной работы является экспериментальное исследование процесса нестационарного горения горючей смеси.

В соответствии с целью необходимо решить следующие задачи:

- разработать конструкцию установки для проведения экспериментального исследования нестационарного горения; 


\section{ЭКСПЕРИМЕНТАЛЬНОЕ ИССЛЕДОВАНИЕ НЕСТАЦИОНАРНОГО ГОРЕНИЯ ПРОПАНО-ВОЗДУШНОЙ СМЕСИ В ТРУБЕ С КОЛЬЦЕВЫМИ ПЕРЕГОРОДКАМИ}

- разработать методику проведения экспериментального исследования;

- провести экспериментальное исследование и проанализировать полученные экспериментальные данные. В результате анализа результатов необходимо определить влияние различного числа перегородок и источников воспламенения с различной энергией на скорость нестационарного горения.

- выполнить проверку адекватности компьютерной модели на экспериментальных данных, полученных на установке.

\section{УСТАНОВКА ДЛЯ ПРОВЕДЕНИЯ ЭКСПЕРИМЕНТАЛЬНОГО ИССЛЕДОВАНИЯ НЕСТАЦИОНАРНОГО ГОРЕНИЯ}

Экспериментальные исследования нестационарного горения, сопоставляемые с условиями горения в угольных шахтах, как правило, проводятся в трубах с одним закрытым и одним открытым концом [7-9]. Поджиг горючей предварительно перемешанной смеси выполняется у закрытого конца трубы. Препятствиями, турбулизирующими горение, являются кольцевые перегородки, регулярно расположенные по длине трубы, поскольку их геометрия наилучшим образом соответствует геометрии крепи шахт. Параметрами перегородок являются шаг установки S, пропорциональный диаметру трубы D, и степень затенения сечения кольцевыми перегородками BR (отношение площади препятствия к площади поперечного сечения трубы) (Рисунок 1). Параметр $S$ в известных исследованиях изменяется в пределах от 0,25D до 2D. Степень затенения меняется в пределах от 0,1 до 0,75 .

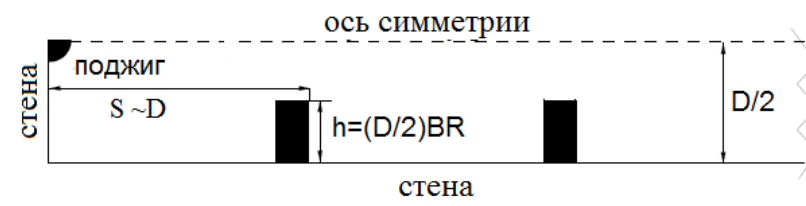

Рисунок 1 - Схема размещения регулярных препятствий

При проведении экспериментов в качестве горючего было предложено использовать имеющейся в наличии пропан и выполнять исследование для стехиометрической пропано-воздушной смеси. По результатам исследования необходимо получить экспериментальные данные о скорости распространения фронта пламени в зависимости от числа перегородок и энергии источника зажигания. На основе анализа экспериментальных данных необходимо определить влияние различного числа перегородок и источников воспламенения с различной энергией на скорость нестационарного горения.

Для проведения исследования разработана экспериментальная установка, позволяющая измерять скорость распространения фронта горения пропано-воздушной смеси. Функциональная схема экспериментальной установки представлена на рисунке 2.

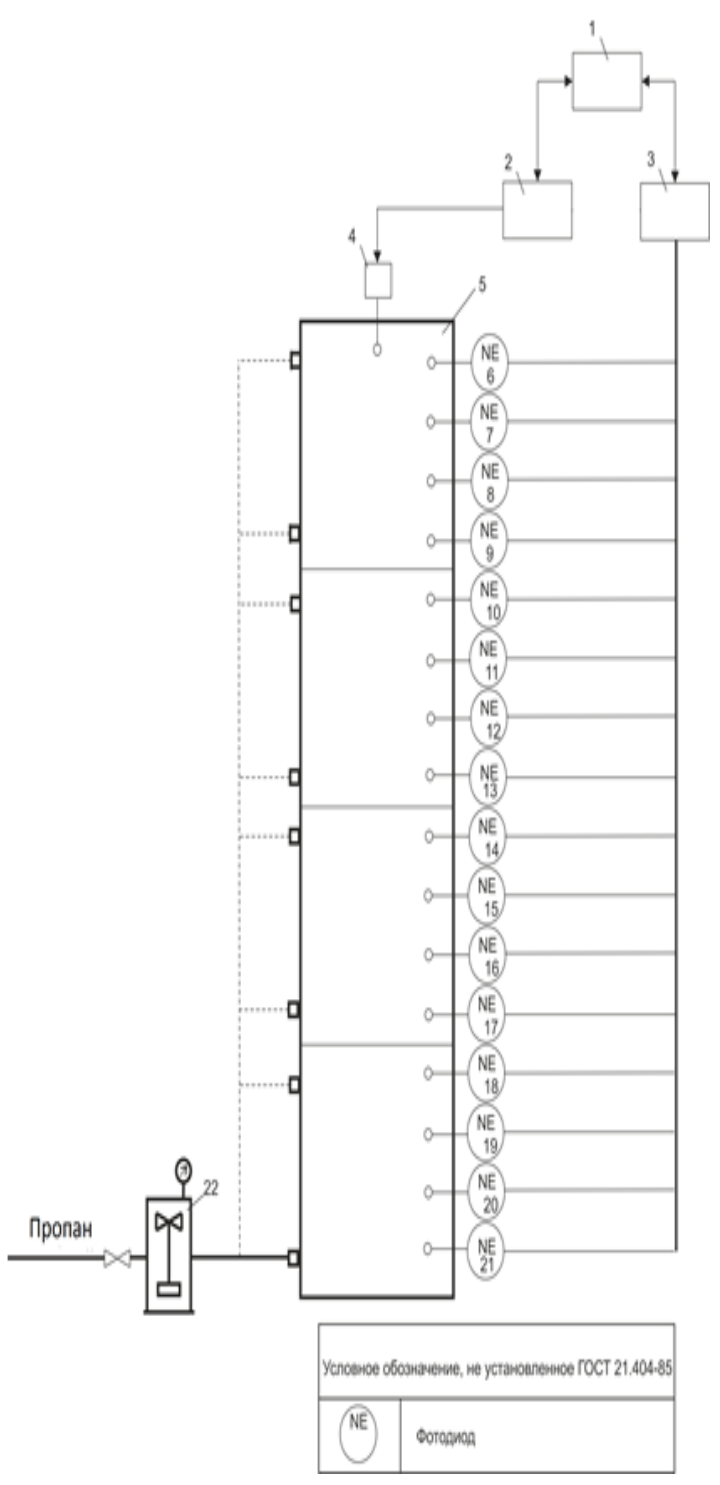

1 - персональный компьютер; 2 - удаленный пульт управления; 3 - модуль АЦП LTR11; 4 - система воспламенения; 5 - реакционный сосуд установки; 6-21 - измерительные датчики; 22 - расходомер

Рисунок 2 - Функциональная схема установки для проведения экспериментальных исследований 


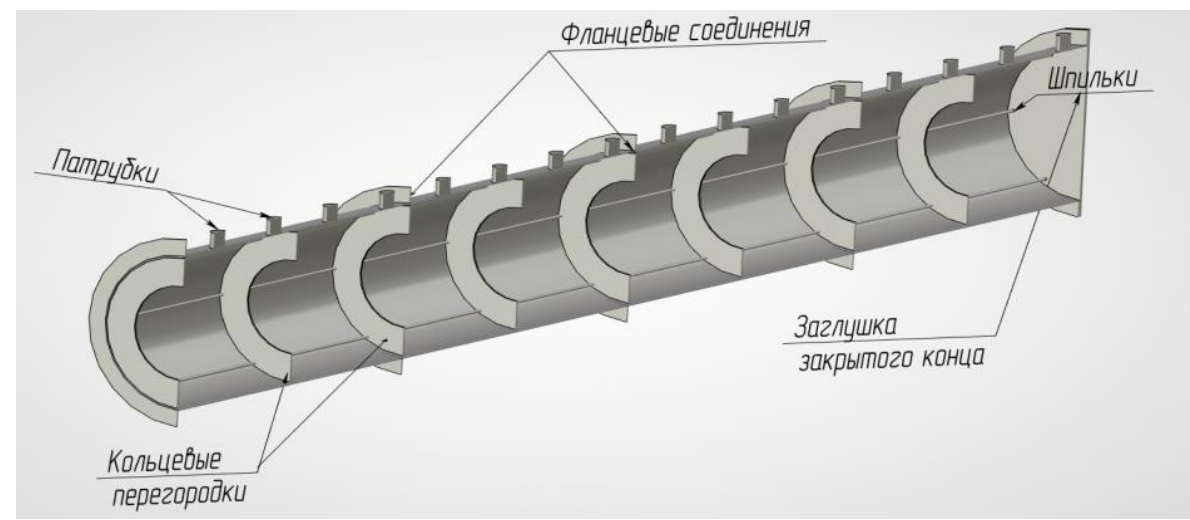

Рисунок 3 - Конструкция реакционного сосуда

Экспериментальная установка содержит реакционный сосуд, заполняемый требуемым объемом горючего газа - пропана. Количество газа, поступающего в сосуд, контролируется с помощью расходомера. Что позволяет точно задать требуемую концентрацию пропана. Для равномерного заполнения используется 8 патрубков для подвода газа, распределённых по длине реакционного сосуда. Поджиг газа осуществляется дистанционно системой воспламенения.

По длине экспериментальной установки расположены 16 точек регистрации мгновенной скорости фронта пламени (фотодиодных датчиков). Сигналы с фотодиодных датчиков регистрируются с помощью автоматизированной измерительной системы, состоящей из предварительных усилителей, модуля аналого-цифрового преобразования и персонального компьютера.

Автоматизированная измерительная система осуществляет следующие функции:

- предварительное усиление сигналов с фотодиодных датчиков;

- аналогово-цифровое преобразование сигналов фотодиодных датчиков;

- запуск системы воспламенения;

- регистрация измерительных данных;

- синхронизация работы функциональных блоков системы.

При проектировании геометрические размеры реакционного сосуда и кольцевых препятствий устанавливались исходя из анализа известных экспериментальных исследований [7-10], по результатам которого определены геометрические параметры труб и кольцевых препятствий, оказывающие эффрективный турбулизирующий эфффект на ускорение пламени.

Ускорение пламени эфффективно на диаметрах труб, превышающих 0,1 м при степе- ни затенения от 0,3 до 0,6. Это обусловлено тем, что для диаметров труб, меньших 0,1 м, эфффективное ускорение пламени обеспечивается только использованием препятствий специальной формы [10]. Также это связано с тем, что на начальной стадии ускорение пламени наиболее эфффективно для больших степеней затенения. Однако при дальнейшем ускорении для больших степеней затенения ускорение замедляется из-за увеличения потерь импульса на препятствиях. Кроме того, для обеспечения переноса результатов экспериментов в детонационной трубе на угольную шахту желательно использование трубы бо́льшего диаметра. Достаточно большой диаметр трубы также позволит осуществить экспериментальные исследования оптикоэлектронных датчиков, помещая их внутрь реакционного сосуда. При этом необходимо обеспечить удобство обслуживания установки и ее мобильность. Исходя из указанных соображений внутренний диаметр трубы (реакционного сосуда) был выбран равным 0,5 м при общей длине 4 м. Для удобства транспортировки реакционный сосуд состоит из четырех цилиндрических блоков, скрепленных фрланцевым соединением (рисунок 3).

Поскольку экспериментальная установка представляет собой сосуд, работающий под внутренним избыточным давлением (до 1 МПа [2]), толщина стенки должна составлять не менее 3 мм в соответствии с расчетами по ГОСТ Р 52857.2-2007 [11].

С одного конца реакционный сосуд заглушен металлической крышкой, с другого конца - загерметизирован пленочной мембраной для обеспечения возможности заполнения горючим газом. Внутри труба содержит кольцевые перегородки (рисунок 4), предназначенные для турбулизации пламени, с параметрами $S=0.5$ м и $B R=0.3$. Указанные па- 


\section{ЭКСПЕРИМЕНТАЛЬНОЕ ИССЛЕДОВАНИЕ НЕСТАЦИОНАРНОГО ГОРЕНИЯ ПРОПАНО-ВОЗДУШНОЙ СМЕСИ В ТРУБЕ С КОЛЬЦЕВЫМИ ПЕРЕГОРОДКАМИ}

раметры перегородок обеспечивают оптимальные условия развития взрывного горения. Перегородки соединяются между собой шпильками.

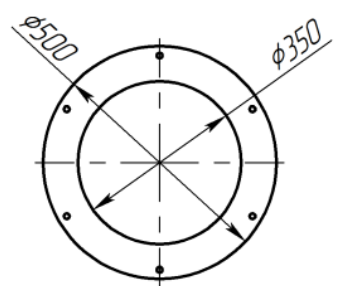

Рисунок 4 - Кольцевая перегородка

Поджиг выполняется у закрытого конца сосуда. В качестве воспламенителей используются электровоспламенитель - пережигаемая электрическим током вольфрамовая нить с энергией 0,5 Дж и пиротехнический воспламенитель с энергией 30 Дж.

Энергия электровоспламенителя в виде пережигаемой вольфрамовой нити определялась путем интегрирования по времени произведения осциллограмм тока и напряжения при ее пережигании в соответствии с ГОСТ Р МЭК 61241-2-3-99 [12]:

$$
W=\int I(t) U(t) d t
$$

Фотодиодные датчики с помощью пробки 1, устанавливаются в патрубки 2 реакционного сосуда (рисунок 5). Фотодиодный датчик представляет собой пару фотодиодов, расположенных по направлению распространения фронта пламени (вдоль трубы) на расстоянии 15 мм друг от друга. Фотодиоды 4 с помощью гильзы 3 вынесены на расстояние 100 мм от края сосуда для уменьшения углового поля с целью более точного определения момента прохождения фронта пламени.

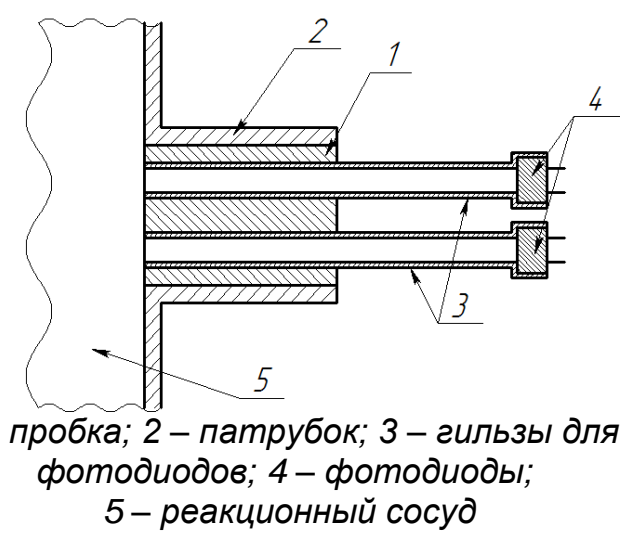

Рисунок 5 - Схема размещения фротодиодных датчиков

В качестве модуля аналого-цифрового преобразования используется модуль L-783 фирмы L-card [13]. Запуск системы воспламенения выполняется с помощью удаленного пульта управления. Регистрация измерительной информации и синхронизация работы функциональных блоков системы осуществляются с помощью персонального компьютеpa.

На испытания установка поставляется в следующей комплектации:

- корпус установки (четыре цилиндрических блока, кольцевые перегородки);

- газовые шланги, баллон с газом, редуктор, расходомер;

- электровоспламенители и пиротехнические воспламенители;

- 16 датчиков скорости перемещения фронта пламени;

- автоматизированная измерительная система;

- кабели для организации линий связи, инициирования воспламенителя и питания.

На рисунке 6 представлена фотография установки, подготовленной к проведению испытания, и кадр видеосъемки при горении газа.

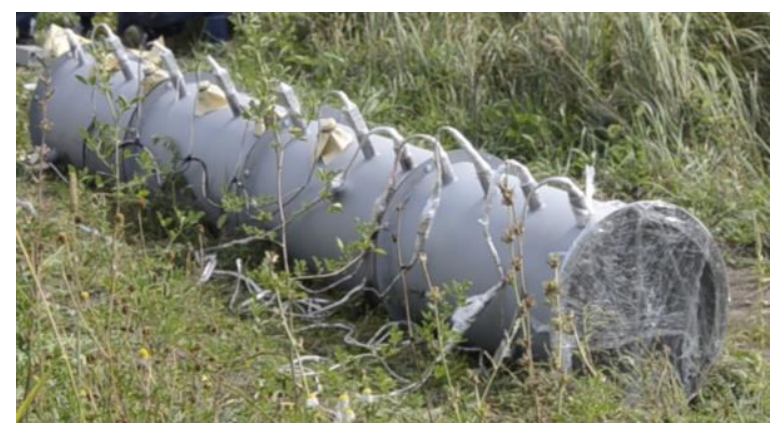

a

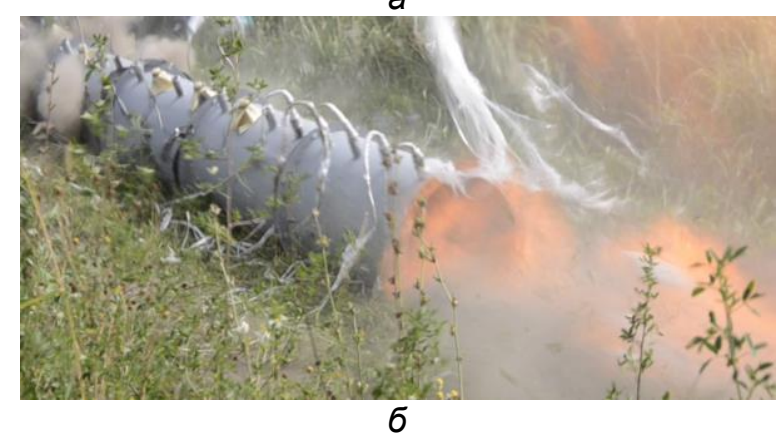

а - экспериментальная установка в сборе; б - экспериментальная установка в момент взрыва

Рисунок 6 - Фотографии экспериментальной установки

\section{МЕТОДИКА ПРОВЕДЕНИЯ} ЭКСПЕРИМЕНТАЛЬНОГО ИССЛЕДОВАНИЯ 
Методика проведения испытаний заключается в выполнении следующих действий:

1. Установить на стапель цилиндрические блоки, соединить блоки фрланцевым соединением.

2. Реакционный сосуд в сборе жестко закрепить на стапеле, исключив продольные и поперечные перемещения.

3. Смонтировать датчики скорости фронта пламени в патрубки установки и подсоединить к ним измерительные линии.

4. Установить воспламенитель через патрубок у заглушенного конца реакционного сосуда.

5. Перед проведением испытаний провести проверку готовности экспериментальной установки.

5.1 Проверить готовность системы инициирования процесса:

- подключить линию инициирования к воспламенителю;

- проконтролировать исправность воспламенителя;

- отключить линию инициирования от воспламенителя.

5.2 Проверить готовность измерительных линий и системы регистрации: ков;

- зарегистрировать сигналы всех датчи-

- сравнить полученные сигналы с ожидаемыми в начальный момент испытаний.

6. После подтверждения готовности системы инициирования, измерительных линий и системы регистрации установить на открытом конце установки плёночную мембрану, препятствующую свободному выходу газа из реакционного сосуда.

7. Подать в реакционный сосуд заданный

Таблица 1. Условия проведения опытов

\begin{tabular}{|l|c|c|c|}
\hline № опыта & $\begin{array}{c}\text { Число пе- } \\
\text { регородок }\end{array}$ & Тип воспламенителя, энергия, Дж & $\begin{array}{c}\text { Максимальная ско- } \\
\text { рость горения, м/с }\end{array}$ \\
\hline 1 & 1 & Электровоспламенитель, 0,5 Дж & 35 \\
\hline 2 & 1 & Пиротехнический воспламенитель, 30 Дж & 100 \\
\hline 3 & 1 & Пиротехнический воспламенитель, 30 Дж & 140 \\
\hline 4 & 2 & Пиротехнический воспламенитель, 30 Дж & 15 \\
\hline 5 & 2 & Пиротехнический воспламенитель, 30 Дж & 160 \\
\hline 6 & 2 & Пиротехнический воспламенитель, 30 Дж & 110 \\
\hline 7 & 3 & Электровоспламенитель, 0,5 Дж & 120 \\
\hline 8 & 3 & Электровоспламенитель, 0,5 Дж & 150 \\
\hline 9 & 4 & Электровоспламенитель, 0,5 Дж & 240 \\
\hline 10 & 7 & Электровоспламенитель, 0,5 Дж & \\
\hline
\end{tabular}

объём газа из баллона через редуктор РВ-90, настроенный на давление 40 кгс/см2, и расходомер газа Гранд 1.6: по 6 м3 пропана в каждый из восьми патрубков подачи газа.

8. Выдержать паузу 15 минут для перемешивания пропана с воздухом в реакционном сосуде.

9. Подключить линию инициирования к системе запуска и дистанционно с пульта управления осуществить запуск процесса.

10. Выполнить регистрацию измеряемых параметров с помощью аналого-цифрового преобразователя и компьютера.

При проведении исследования изменяется число используемых перегородок и тип воспламенителя (пережигаемая электрическим током вольфрамовая нить и пиротехнический воспламенитель). Перегородки устанавливаются с шагом 0,5 м от закрытого конца трубы: первая на расстоянии 0,5 м, вторая -1 м и т.д.

\section{РЕЗУЛЬТАТЫ ЭКСПЕРИМЕНТАЛЬНОГО ИССЛЕДОВАНИЯ}

Экспериментальное исследование проводилось на базе испытательной площадки предприятия АО «ФНПЦ «Алтай» по договору НИР №2129/17. При выполнении экспериментального исследования проведено 10 опытов с нестационарным горением пропановоздушной смеси.

Условия проведения опытов представлены в таблице 1.

Результаты экспериментального исследования в виде зависимостей скорости фронта пламени по длине установки для проведенных опытов представлены на рисунке 7. 


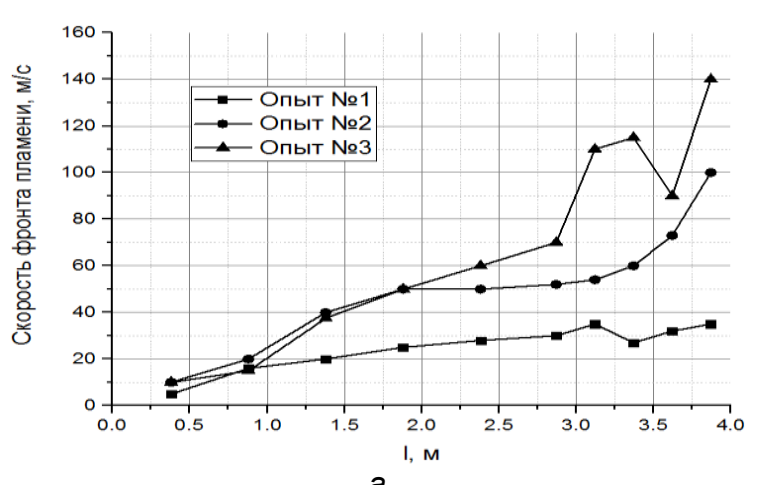

a

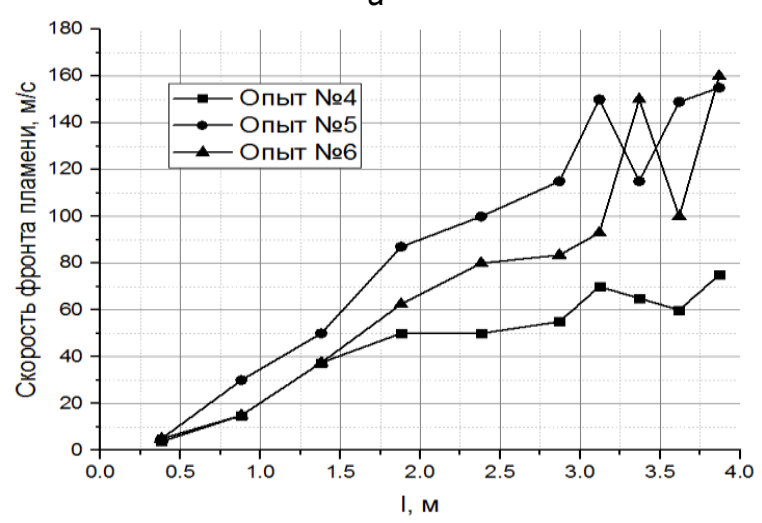

6

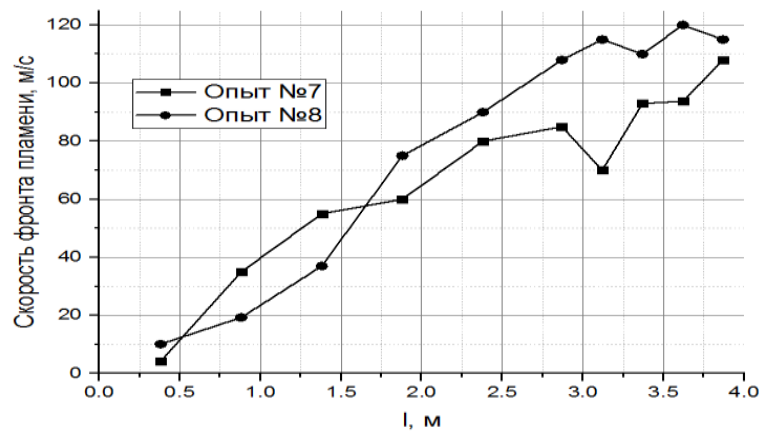

8

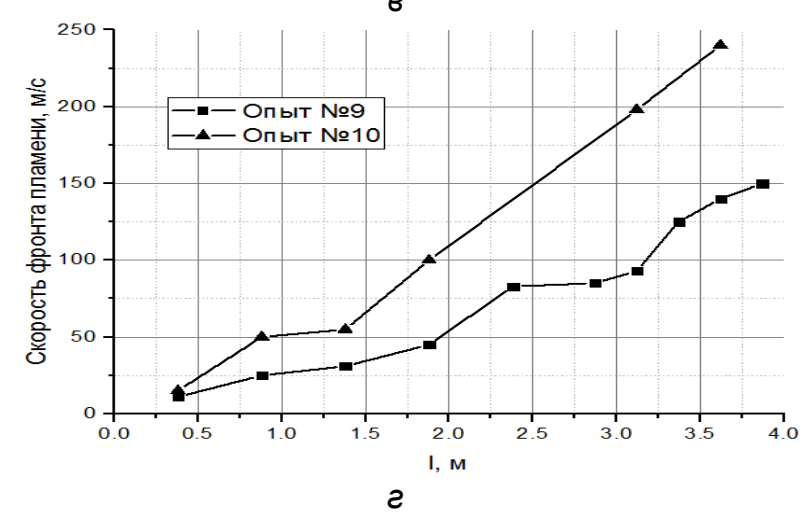

a- опыты 1, 2, 3 с одной перегородкой;

б- опыты 4, 5, 6 с двумя перегородками;

в- опыты 7, 8 с тремя перегородками;

г- опыты 9 и 10 с 4 и 7 перегородками соответственно

Рисунок 7 - Зависимость скорости фронта пламени по длине установки
На рисунке 7а показаны зависимости для одной перегородки. При этом максимальная скорость фрронта при использовании электровоспламенителя (опыт № 1) достигает $35 \mathrm{~m} / \mathrm{c}$, а при использовании пиротехнического воспламенителя с большей энергией зажигания максимальная скорость возрастает - до 140 м/с. Опыты № 2 и 3 проводились в одинаковых условиях и полученные результаты хорошо согласуются между собой.

На рисунке $7 б$ показаны зависимости для двух перегородок при применении пиротехнического воспламенителя. Из результатов видно, что опыты № 5 и 6 удовлетворительно согласуются между собой. При этом максимальная скорость фронта пламени составляет 160 м/с. В опыте № 4 максимальная скорость не превысила $75 \mathrm{~m} / \mathrm{c}$ и не согласуется с опытами 5 и 6. Это может быть связано с нарушением условий проведения экспериментов, а именно отклонением концентрации смеси от стехиометрической из-за разгерметизации реакционного сосуда установки.

Данные о скорости фронта пламени по длине трубы, полученные при использовании трех перегородок и электровоспламенителя приведены на рисунке 7в. Максимальная скорость фронта пламени, полученная в опытах, составляет 120 м/с. Опыты № 7 и 8 проводились в одинаковых условиях и их результаты хорошо согласуются между собой.

На рисунке 7г приведены результаты опыта №9 при использовании четырех перегородок и результаты опыта №10 для семи перегородок. Воспламенение смеси в данных опытах производилось электровоспламенителем. В опыте №9 максимальная скорость фрронта пламени достигает 150 м/с, а в опыте № $10-240 \mathrm{~m} / \mathrm{c}$.

Зависимость максимальной скорости фронта пламени от числа перегородок, полученной в опытах при воспламенении горючей смеси электровоспламенителем приведена на рисунке 8.

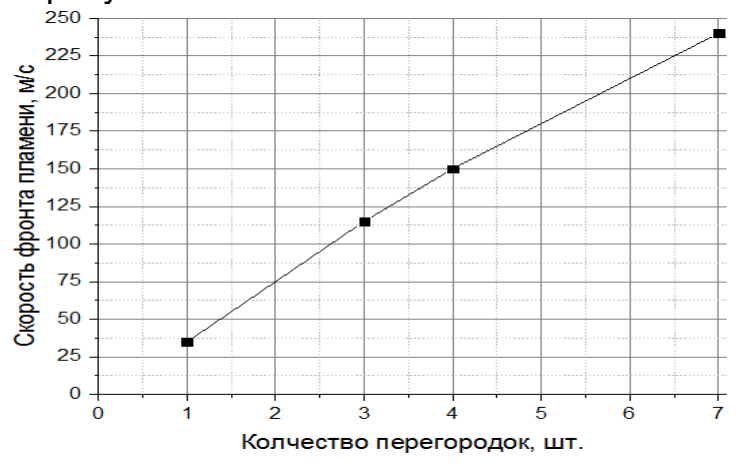

Рисунок 8 - Зависимость максимальной скорости фронта пламени от числа перегородок при воспламенении электровоспламенителем 
В результате анализа результатов экспериментов определено влияние различного числа перегородок и источников воспламенения с различной энергией на скорость нестационарного горения

При использовании пиротехнического воспламенителя с большей по сравнению с электровоспламенителем энергией зажигания (в 60 раз) максимальная скорость фрронта пламени увеличивается в 4 раза.

Для опытов при использовании электровоспламенителя с увеличением числа перегородок максимальная скорость фронта пламени практически линейно возрастает от 35 м/с для одной перегородки до 240 м/с для семи перегородок. Из зависимости видно, что при добавлении одной дополнительной перегородки максимальная скорость фронта пламени увеличивается приблизительно на $35 \mathrm{~m} / \mathrm{c}$.

Полученная зависимость скорости фронта пламени от числа перегородок согласуется с результатами исследований других авторов, приведенных в работах $[14,15]$. В работе [14] рассматривалось влияние числа перегородок прямоугольной фрормы (от 1 до 3) на скорость распространения фрронта пламени в трубе квадратного сечения. В данных исследованиях максимальная скорость фронта пламени увеличивалась приблизительно на 20 м/с с добавлением дополнительной перегородки.

\section{ПРОВЕРКА АДЕКВАТНОСТИ КОМПЬЮТЕРНОГО МОДЕЛИРОВАНИЯ}

В работах $[1,2]$ изложены подходы к компьютерному моделированию процесса нестационарного горения углеводородовоздушных смесей для условий, характерных для угольных шахт. Для моделирования турбулентного течения используется модель на базе осредненных нестационарных (URANS) уравнений Навье-Стокса. Для турбулентных переменных k и $\varepsilon$ используется стандартная $\mathrm{k}-\varepsilon$ модель. Модель горения основана на одностадийной необратимой брутто реакции горения. Скорость брутто реакции описывается моделью вихревой диссипации (EDM), представленную в работе [16]. В качестве модели переноса энергии излучением используется диффузионная модель Р-1. Расчет коэффициента поглощения продуктов горения осуществляется на базе модели взвешенной суммы серых газов (ВССГ) [1, 2].

Компьютерное моделирование выполнялось с помощью специализированного программного обеспечения FlowVision $[17,18]$ в двумерной постановке для исходных данных, соответствующих проведению эксперимента (таблица 2).

Таблица 2. Исходные данные для проведения моделирования

\begin{tabular}{|c|c|}
\hline Параметр & Значение \\
\hline Граничные условия & $\begin{array}{l}\text { Труба диаметром } \\
0,5 \text { м с одним закры- } \\
\text { тым и одним откры- } \\
\text { тым концом и коль- } \\
\text { цевыми перегород- } \\
\text { ками с параметрами } \\
\text { S=0,5; BR=0,3, под- } \\
\text { жиг располагается у } \\
\text { закрытого конца. } \\
\text { Количество кольце- } \\
\text { вых перегородок - } 7\end{array}$ \\
\hline $\begin{array}{ll}\text { Температура } & \text { вос- } \\
\text { пламенения } \\
\text { поджига) }\end{array}$ & $650^{\circ} \mathrm{C}$ \\
\hline 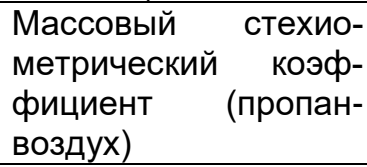 & 15,6 \\
\hline Температура смеси & $20^{\circ} \mathrm{C}$ \\
\hline Давление & $10^{5} \Pi a$ \\
\hline
\end{tabular}

Для двумерной постановки задачи высота кольцевого препятствия определялась, как $\mathrm{h}=(\mathrm{D} / 2) \cdot \mathrm{BR}$ согласно [11] (рисунок 1).

Для проверки адекватности результаты компьютерного моделирования были сопоставлены с экспериментальных данными о зависимости скорости распространения фронта пламени от длины установки (рисунок 9).

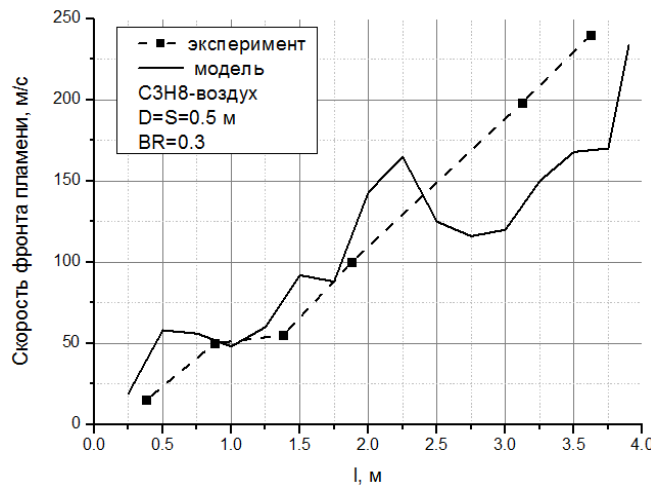

Рисунок 9 - Распределение скорости фронта пламени по длине установки

Экспериментальные данные о скорости фронта пламени и результаты расчетов на базе компьютерного моделирования хорошо согласуются друг с другом. Относительная погрешность расчета скорости не превышает $18 \%$. Расхождения могут быть обусловлены неучтенными в модели потерями энергии, а

ПОЛЗУНОВСКИЙ ВЕСТНИК № 22018 


\section{ЭКСПЕРИМЕНТАЛЬНОЕ ИССЛЕДОВАНИЕ НЕСТАЦИОНАРНОГО ГОРЕНИЯ ПРОПАНО-ВОЗДУШНОЙ СМЕСИ В ТРУБЕ С КОЛЬЦЕВЫМИ ПЕРЕГОРОДКАМИ}

также объемными эффректами в реальной трехмерной трубе, не учитываемыми при двумерном моделировании.

По результатам проверки адекватности можно сделать вывод о том, что разработанная авторами компьютерная модель [1, 2] применима для расчета параметров нестационарного горения пропано-воздушных смесей в трубах с регулярными препятствиями.

\section{ЗАКЛЮЧЕНИЕ}

В результате выполнения работ проведено экспериментальное исследование процесса нестационарного горения пропановоздушной смеси.

Решены следующие задачи:

- разработана конструкция установки для проведения экспериментального исследования нестационарного горения;

- разработана методика проведения экспериментального исследования;

- проанализированы полученные экспериментальные данные;

- выполнена проверка адекватности компьютерной модели на экспериментальных данных, полученных на установке.

Конструкция установки содержит реакционный сосуд и автоматизированную измерительную систему. Реакционный сосуд экспериментальной установки представляет собой трубу с одним открытым концом, внутренним диаметром 0,5 м и длиной 4 метра. В реакционном сосуде размещались кольцевые перегородки с шагом установки $S=0.5$ м и степенью затенения сечения $\mathrm{BR}=0.3$. Автоматизированная измерительная система выполняет запуск эксперимента и регистрирует сигналы фотодиодных датчиков для последующего определения скорости фронта пламени.

Методика экспериментального исследования заключалась в: подготовке экспериментальной установки к опыту; подаче пропана в реакционный сосуд; воспламенении смеси; выполнении регистрации измерительных данных.

Исследование проводилось для различного числа используемых перегородок и типов воспламенителей (электровоспламенитель и пиротехнический воспламенитель).

При использовании пиротехнического воспламенителя с большей энергией зажигания, чем у электровоспламенителя (0,5 Дж и 30 Дж соответственно) максимальная скорость возрастает в 4 раза.

С увеличением числа перегородок максимальная скорость фронта пламени практически линейно возрастает от 35 м/с для од- ной перегородки до 240 м/с для семи перегородок. При добавлении одной дополнительной перегородки максимальная скорость фронта пламени увеличивается приблизительно на 35 м/с.

Разработанная компьютерная модель является адекватной и применима для расчета параметров нестационарного горения пропано-воздушных смесей в трубах с регулярными препятствиями. Относительная погрешность расчета скорости фронта пламени не превышает $18 \%$.

Дальнейшая работа направлена на проведение экспериментальных исследований для перегородок с другими геометрическими параметрами. Также в ходе экспериментов предполагается дополнительно измерять температуру и давление в реакционном сосуде.

Исследование выполнено при фринансовой поддержке РФФИ в рамках гранта №1708-00844.

\section{СПИСОК ЛИТЕРАТУРЫ}

1. Постановка задачи моделирования процесса нестационарного горения метановоздушной смеси в угольных шахтах / С.А. Лисаков, Е.В. Сыпин, Н.Ю. Тупикина, Ю.А. Галенко // Вестник Научного центра по безопасности работ в угольной промышленности. - 2017. - № 4 (Принято в печать).

2. Моделирование процесса нестационарного горения метано-воздушной смеси в угольных шахтах / С.А. Лисаков, Е.В. Сыпин, М.Н. Зырянова, А.Н. Павлов, Ю.А. Галенко // Вестник Научного центра по безопасности работ в угольной промышленности. - 2017. - № 4 (Принято в печать).

3. Программно-аппаратный комплекс для управления многоточечной системой определения координат очага возгорания / Лисаков С.А., Кураев A.В., Сыпин Е.В., Павлов А.Н. // Ползуновский вестник. -2014. - № 2. - С. 179-182.

4. Weiss, E. S., Cashdollar, K. L., Mutton, I. V. S., Kohli, D. R., \& Slivensky, W. A. (1999) Evaluation of reinforced cementitious seals (35 pp.). NIOSH RI 9647.

5. Sapko, M. J., Weiss, E. S., \& Watson, R. W. (1987b) Size scaling of gas explosions (23 pp.). U.S. Bureau of Mines RI 9136.

6. Васючков Ю. Ф. Горное дело: Учеб. для техникумов / Ю. Ф. Васючков. - М.: Недра, 1990. $512 \mathrm{c}$.

7. Kuznetsov, M., Ciccarelli G., Dorofeev S., Alekseev V., Yankin Yu, and Kim T. H. DDT in Methane-Air Mixtures, Shock Waves, Vol. 12, 2002, pp. 215-220.

8. V. N. Gamezo, R. K. Zipf, Jr., D. A. Kessler, E. S. Oran. DDT in Natural Gas-Air Mixtures on Large Scales: Experiments and Simulations, 24th ICDERS, 2013, Taipei, Taiwan, pp. 1-6.

9. E.S. Oran, V.N. Gamezo, and D.A. Kessler 
Deflagrations, Detonations, and the Deflagration-toDetonation Transition in Methane-Air Mixtures, Naval Research Laboratory, Washington, DC, 2011, 125 p.

10. Ускорение перехода горения в детонацию в газах: от К. И. Щёлкина до наших дней/ С. М. Фролов // Физика горения и взрыва. - 2012. - № 3. C. 13-24.

11. ГОСТ Р 52857.2-2007 Сосуды и аппараты. Нормы и методы расчета на прочность. Расчет цилиндрических и конических обечаек, выпуклых плоских и днищ и крышек [Текст]. - М.: Стандартинформ, 2008.

12. ГОСТ Р МЭК 61241-2-3-99 Электрооборудование, применяемое в зонах, опасных по воспламенению горючей пыли. Часть 2. Методы испытаний. Раздел 3. Метод определения минимальной энергии зажигания пылевоздушных смесей. Гостстандларт России, Москва. 1999. - 16 с.

13. ООО «Л КАРД» [Электронный ресурс] / Индустриальные системы управления и сбора данных. - Режим доступа: http://www.lcard.ru/

14. Zhiming, Q.U., 2010. Numerical study on shock wave propagation with obstacles during methane explosion. Appl. Mech. Mater. Trans Tech Publ. 114e118.

15. S. K. Kundu, J. Zanganeh. A Review on Understanding Explosions from Methane-Air Mixture. Journal of Loss Prevention in the Process Industries 40, 2016, pp. 507-523.

16. Magnussen B.F., and Hjertager B.H. (1976) "On Mathematical Modelling of Turbulent Combustion with Special Emphasis on Soot Formation and Combustion," Sixteenth Symposium (International) on Combustion, pp. 719-729.

17. FlowVision. Версия 3.09.04. Руководство пользователя [Электронный ресурс]. - Режим доступа: $\quad$ https://flowvision.ru/index.php/publicdownloads/category/8dokumentatsiyaflowvision? download=112:3-09-04-pdf-enu
18. Маркова, Т.В. Развитие моделей горения в ПК flowvision [Электронный ресурс]. - Режим доступа:

http://tesis.com.ru/infocenter/downloads/flowvision/fv_ es12_tesis3.pdf

Лисаков Сергей Анатольевич, инженер каф. МСИА, БТИ (фрилиал) ФГБОУ ВПО "АлтГТУ им. И.И. Ползунова», Россия, 659305, Бийск, ул. Трофимова 27, тел.: (3854) 432450, e-mail: foxlsa@mail.ru

Сидоренко Антон Игоревич, канд. техн. наук, доцент каф. МСИА, БТИ (филиал) ФГБОУ ВПО «АлтГТУ им. И.И. Ползунова», Россия, 659305, Бийск, ул. Трофимова 27, тел.: (3854) 432450, e-mail: pan@bti.secna.ru

Сыпин Евгений Викторович, канд. техн. наук, профрессор каф. МСИА, БТИ (фоилиал) ФГБОУ ВПО «АлтГТУ им. И.И. Ползунова», Россия, 659305, Бийск, ул. Трофримова 27, тел.: (3854) 432450, e-mail: sev@bti.secna.ru

Галенко Юрий Анатольевич, о.фр.-м.н, профрессор, БТИ (филиал) ФГБОУ ВПО «АлтГТУ им. И.И. Ползунова», Россия, 659305, Бийск, ул. Трофримова 27, тел.: (3854) 432450, E-mail: gal@bti.secna.ru

Павлов Андрей Николаевич, канд. техн. наук, доцент каф. МСИА, БТИ (филиал) ФГБОУ ВПО «АлтГТУ им. И.И. Ползунова», Россия, 659305, Бийск, ул. Трофимова 27, тел.: (3854) 432450, e-mail: pan@bti.secna.ru 